\title{
Women in Engineering as a Research Topic: Past, Present, and Future
}

\section{IEEE TEMSCON CONFERENCE 2021}

\author{
Marina Dabić \\ Faculty of Economics and Business \\ University of Zagreb \\ Zagreb, Croatia \\ mdabic@net.efzg.hr \\ $\&$ \\ Management Division \\ Nottingham Trent University \\ Nottingham, UK \\ marina.dabic@ntu.ac.uk \\ Božidar Vlačić \\ Católica Porto Business School and CEGE \\ Universidade Católica Portuguesa \\ Porto, Portugal \\ bvlacic@ porto.ucp.pt \\ Tena Obradović \\ Faculty of Economics and Business \\ University of Zagreb \\ Zagreb, Croatia \\ tobradovic@net.efzg.hr \\ Giacomo Marzi \\ Lincoln International Business School \\ University of Lincoln \\ Lincoln, UK \\ gmarzi@lincoln.ac.uk \\ Sascha Kraus \\ Free University of Bozen-Bolzano \\ Faculty of Economics and Management \\ Bozen-Bolzano, Italy \\ sascha.kraus@unibz.it
}

\begin{abstract}
This study explores the extent to which women are part of the engineering research domain, what their current position in this is, and what the fundamental reasons for (in)equality are in this regard. For this integrative literature review, publication data indexed in Scopus was used. A search on the topic of women (in)equality in top journals, defined as level 3 or above according to the British Chartered Association of Business Schools (ABS) journal ratings, yielded 61 results. The following bibliometric analysis revealed six clusters of keywords which outlined the intellectual structure of women in engineering. By encouraging women to engage in science and engineering, society can influence gender equality and prevent further gender differences. Companies can also benefit from diversified talent pools by achieving greater competitiveness.
\end{abstract}

Keywords - women status, literature review, female, engineering, science mapping. 